\title{
Autopalmitoylation of tubulin
}

\author{
J. WOLFF, ANNA MARIA ZAMBITO, P. JERAM BRITTO, AND LESLIE KNIPLING \\ Laboratory of Biochemistry and Genetics, NIDDK, NIH, Bethesda, Maryland 20892
}

(Received January 17, 2000; Final Revision May 11, 2000; Accepted May 11, 2000)

\begin{abstract}
Pure rat brain tubulin is readily palmitoylated in vitro using $\left[{ }^{3} \mathrm{H}\right]$ palmitoyl CoA but no added enzymes. A maximum of approximately six palmitic acids are added per dimer in $2-3 \mathrm{~h}$ at $36-37{ }^{\circ} \mathrm{C}$ under native conditions. Both $\alpha$ and $\beta$ tubulin are labeled, and 63-73\% of the label was hydroxylamine-labile, presumed thioesters. Labeling increases with increasing $\mathrm{pH}$ and temperature, and with low concentrations of guanidine $\mathrm{HCl}$ or $\mathrm{KCl}$ (but not with urea) to a maximum of $\sim 13$ palmitates/dimer. High SDS and guanidine $\mathrm{HCl}$ concentrations are inhibitory. At no time could all 20 cysteine residues of the dimer be palmitoylated. Polymerization to microtubules, or use of tubulin S, markedly decreases the accessibility of the palmitoylation sites. Palmitoylation increases the electrophoretic mobility of a portion of $\alpha$ tubulin toward the $\beta$ band. Palmitoylated tubulin binds a colchicine analogue normally, but during three warm/cold polymerization/ depolymerization cycles there is a progressive loss of palmitoylated tubulin, indicating decreased polymerization competence. We postulate that local electrostatic factors are major regulators of reactivity of tubulin cysteine residues toward palmitoyl $\mathrm{CoA}$, and that the negative charges surrounding a number of the cysteines are sensitive to negative charges on palmitoyl CoA.
\end{abstract}

Keywords: denaturation; electrostatics; mobility shift; palmitoyl CoA; polymerization

Palmitoylation of proteins, largely on $\mathrm{SH}$ groups of cysteine, is now recognized as a common post-translational modification. In some cases, it must be preceded by $\mathrm{N}$-terminal myristoylation to form an amide bond, or by C-terminal prenylation forming a stable thioether bond with farnesyl or geranylgeranyl groups. These reactions occur sequentially with palmitoylation being second and frequently, but not necessarily, near the earlier lipid modification. A third group of proteins can be palmitoylated without prior lipid modifications, sometimes near a trans-membrane domain (Milligan et al., 1995; Dunphy \& Linder, 1998). More than one such addition per protein molecule may occur (Weimbs \& Stoffel, 1992; Gunderson et al., 1994; Chapman et al., 1996; Tao et al., 1996; Ford et al., 1998). Unlike the other lipid modifications, palmitoylation is reversible and the turnover of the lipid is faster than that of the protein substituted (Omary \& Trowbridge, 1981; Magee et al., 1987). Its postulated hydrophobic contribution to protein association with membranes or other proteins may thus be subject to regulation. The enzymology of the on and off reaction for palmitoylation is only now being elucidated. However, nonenzymatic autoacylation with palmitate has been observed to occur as a confounding factor in some studies. Thus, rhodopsin (O'Brien et al.,

Reprint requests to: J. Wolff, Laboratory of Biochemistry and Genetics, Building 8, Room 2A23, Bethesda, Maryland 20892; e-mail: janw@bdg8. niddk.nih.gov.

Abbreviations: SDS, sodium dodecyl sulfate; CoA, coenzyme A; GuHCl, guanidine hydrochloride; DTNB, 5,5'-dithiobis-(2-nitrobenzoate); EGTA, ethyleneglycol-bis ( $\beta$-aminoethyl ether)- $N, N, N^{\prime}, N^{\prime}$-tetraacetic acid.
1987; Veit et al., 1998), myelin proteolipid protein (Bizzozero et al., 1987), GAP43 (Sudo et al., 1992), myristoylated or unlipidated peptides (Quesnel \& Silvius, 1994; Parente et al., 1985; Bharadwaj \& Bizzozero, 1995), glucuronosyl transferase (Yamashita et al., 1995), actin, some dehydrogenases, and fetuin (Bañó et al., 1998), Po myelin glycoprotein (Bharadwaj \& Bizzozero, 1995), brain protein kinase C (Ford et al., 1998), and certain, but not all $\mathrm{G} \alpha$ proteins (Duncan \& Gilman, 1996), exhibit significant autoacylation with palmitoyl CoA. Such reactions provide a useful model for the nature of, and the conditions for, the reaction mechanism.

It has recently been shown that in the highly water soluble tubulin dimer, both monomers were labeled with $\left[{ }^{3} \mathrm{H}\right]$ palmitate in platelets and in PC 12 pheochromocytoma cells; $\alpha$ tubulin was more extensively labeled than $\beta$ tubulin (Caron, 1997; Zambito \& Wolff, 1997). In PC12 cells, the amount and distribution of label could be regulated by hormones or growth factors. Because of unknown contributions of palmitate from intracellular sources, it was not easy, in these in vivo experiments, to arrive at a meaningful stoichiometry for the palmitate/tubulin-dimer, although the number has to be at least two per dimer since both monomers are labeled. Certain other proteins with multiple SH groups have been palmitoylated partially, but the basis for the resistance of some $\mathrm{SH}$ groups (steric or local electrostatic effects) has not been specified. We therefore employed a nonenzymatic, autoacylation procedure using pure tubulin and labeled palmitoyl CoA to assess the structural requirements for tubulin palmitoylation as a guide to the understanding of in vivo palmitoylation of tubulin. 


\section{Results}

Incubation of pure rat brain tubulin with ${ }^{3} \mathrm{H}$-labeled palmitoyl CoA leads to covalent incorporation of palmitic acid into the protein. Palmitoylation shows a progressive increase up to 2-3 h. There is an initial rapid binding phase occurring before "zero" time samples can be collected such that the curves appear not to pass through the origin (Fig. 1). Whether or not this rapid phase is due to surface exposed cysteine residues or some other form of increased SH reactivity is not known. Moreover, the same phenomenon has been observed by us and others when tubulin SH groups are titrated with DTNB-i.e., several SH groups have already reacted by the time the first reading is taken. SDS gels of these samples show palmitate incorporation into both the $\alpha$ and $\beta$ monomers. This will be elaborated below. At low loads of palmitoyl CoA $(\sim 1 \mu \mathrm{M}$, tubulin $\sim 19 \mu \mathrm{M}), \sim 15-20 \%$ of the label becomes covalently protein bound. However, the actual number of moles of palmitic acid incorporated per mole of dimer is very low, especially when considering that there are potentially 20 cysteine residues available per dimer. High concentrations of palmitoyl CoA (1 $\mathrm{mM})$, providing high mole ratios of palmitate to tubulin, are required to attain significant degrees of palmitate incorporation into tubulin (Fig. 1). Here, too, there is substantial incorporation at "zero" time, followed by a slower increase for several hours. Under the time constraints, ionic strength and $\mathrm{pH}$ used in these experiments, the maximum incorporation of palmitic acid did not exceed $\sim 6-7$ moles per mole of dimer (Fig. 2). Similar results are obtained when the starting mole ratio is increased at fixed palmitoyl CoA concentration by lowering the tubulin concentration (Fig. 2, inset). It is not possible to specify whether or not these mole ratios imply the complete modification of individual SH groups or partial

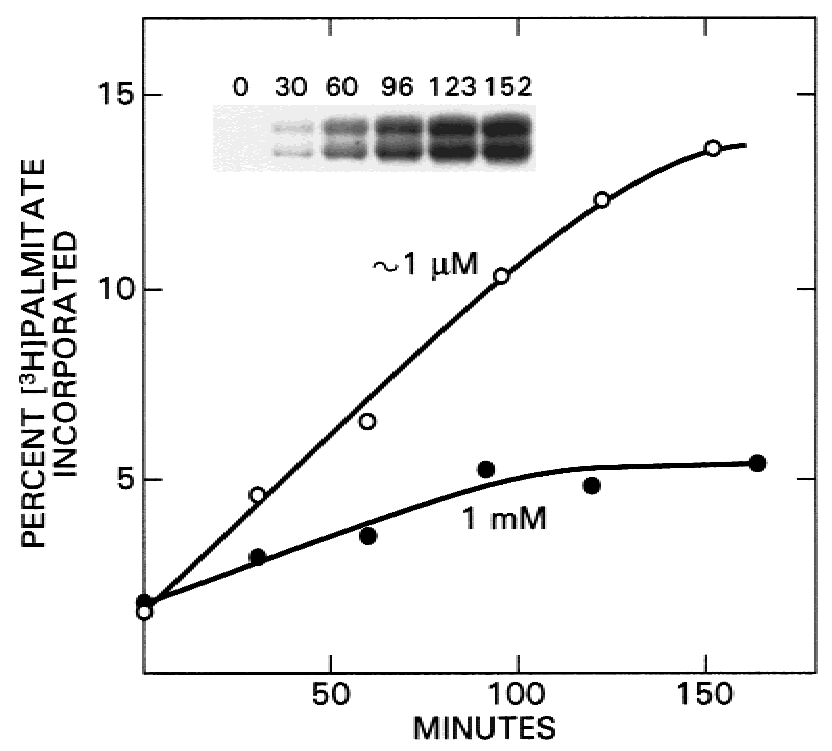

Fig. 1. Time course of palmitoylation of rat brain tubulin. All incubations are at $36^{\circ} \mathrm{C}$ in $0.1 \mathrm{M}$ Tris buffer $\mathrm{pH} 7.6,0.03 \%$ Triton $\mathrm{X}-100,1 \mathrm{mM}$ $\mathrm{MgCl}_{2}$, and no added GTP. Specific activities were adjusted with unlabeled palmitoyl CoA. The $\sim 1 \mu \mathrm{M}$ curve represents the unfortified label. Tubulin was $19.3 \mu \mathrm{M}$. Reactions were stopped with cold $10 \%$ TCA; precipitates were washed to low background and counted. The inset shows a radioautogram for the time course depicted in the upper $(\sim 1 \mu \mathrm{M})$ curve; the numbers indicate minutes of incubation. The lower curve was run at $1 \mathrm{mM}$ palmitoyl CoA.

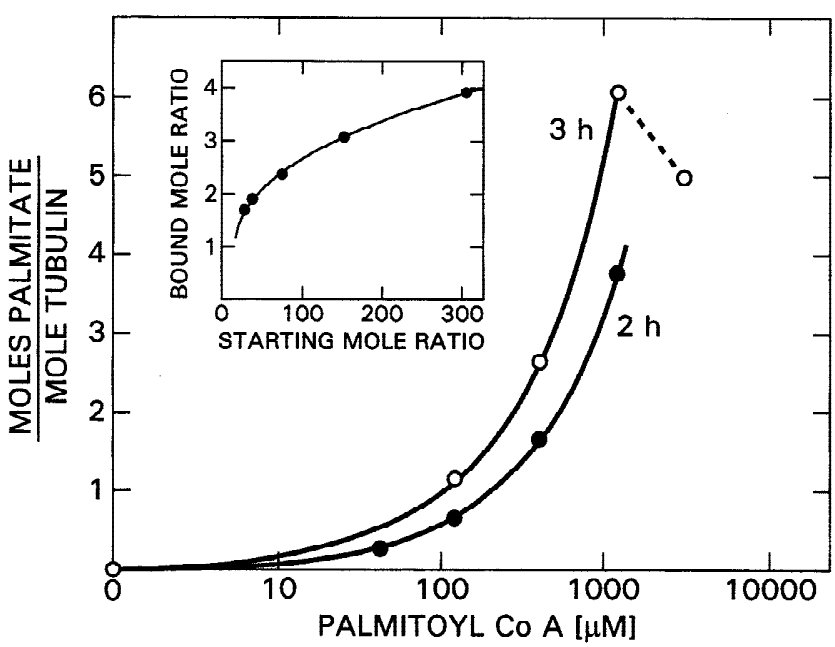

Fig. 2. Concentration dependence of autopalmitoylation of rat brain tubulin. Sixteen micrometers tubulin was incubated at $36^{\circ} \mathrm{C}$ and $\mathrm{pH} 7.5$ with $\left[{ }^{3} \mathrm{H}\right]$ palmitoyl CoA fortified with $\sim 1 \mu \mathrm{M}$ to $1 \mathrm{mM}$ palmitoyl CoA. Mole ratios were calculated from specific activities and percent incorporation. Curves for 2 and $3 \mathrm{~h}$ incubations are depicted. Inset: Autopalmitoylation at $1.0 \mathrm{mM}$ palmitoyl CoA and increasing tubulin concentration (from 128 to 1280 pmol per $40 \mu \mathrm{L}$ ) incubated at $37^{\circ} \mathrm{C}$ for $60 \mathrm{~min}$ and plotted as a function of the starting mole ratio of palmitoyl $\mathrm{CoA} /$ tubulin. Starting and bound mole ratios are moles palmitoyl $\mathrm{CoA}$ or palmitate per mole tubulin dimer.

palmitoylation of a greater number; we are currently developing better methods for analysis of very hydrophobic tryptic peptides. Longer time intervals were not investigated because of the wellknown decay of tubulin at these incubation temperatures.

\section{Solution variables}

The apparent dissociation constants $\left(\mathrm{p} K_{a}\right)$ range from $<8$ to $>10$, depending on the environment of the SH residue (Friedman, 1973; Crampton, 1974); hence the rate and extent of palmitoylation of tubulin during $2 \mathrm{~h}$ of reaction was expected to be sensitive to $\mathrm{pH}$. Palmitoylation occurs primarily via the thiolate anion and increases as a function of $\mathrm{pH}$ as shown in Figure 3A. The effect was not significantly influenced by the nature of the buffer used. At $\mathrm{pH} 10.0$ in $0.1 \mathrm{M}$ glycine buffer in the presence of $1.0 \mathrm{mM}$ palmitoyl CoA, a mole ratio (palmitate/tubulin dimer) of 13.3 was attained after a $2 \mathrm{~h}$ incubation at $37^{\circ} \mathrm{C}$ (data not shown). A similar $\mathrm{pH}$ profile was seen at low palmitoylCoA $(0.7 \mathrm{mM})$ concentrations. However, because of the instability of tubulin at elevated $\mathrm{pH}$ values, we consistently carried out autoacylation reactions at $\mathrm{pH}=7.6$.

Magnesium concentrations $>0.1 \mathrm{mM}$ and $<2.0 \mathrm{mM}$ had little effect on the rate or extent of incorporation of palmitate, whereas large concentrations were inhibitory.

Autoacylation is reduced at low temperatures in various proteins and we have observed this for tubulin as well (Fig. 3B). However, there was still significant palmitoylation at $0{ }^{\circ} \mathrm{C}$, at a starting mole ratio (palmitoyl CoA/tubulin) of 2.5.

To keep liberated free palmitic acid in solution and prevent adsorption of palmitoyl CoA to plastic, etc., nonionic detergents are often used. Under a load of $0.5 \mathrm{mM}$ palmitoyl CoA, incorporation of labeled palmitate was decreased when Triton X-100 con- 

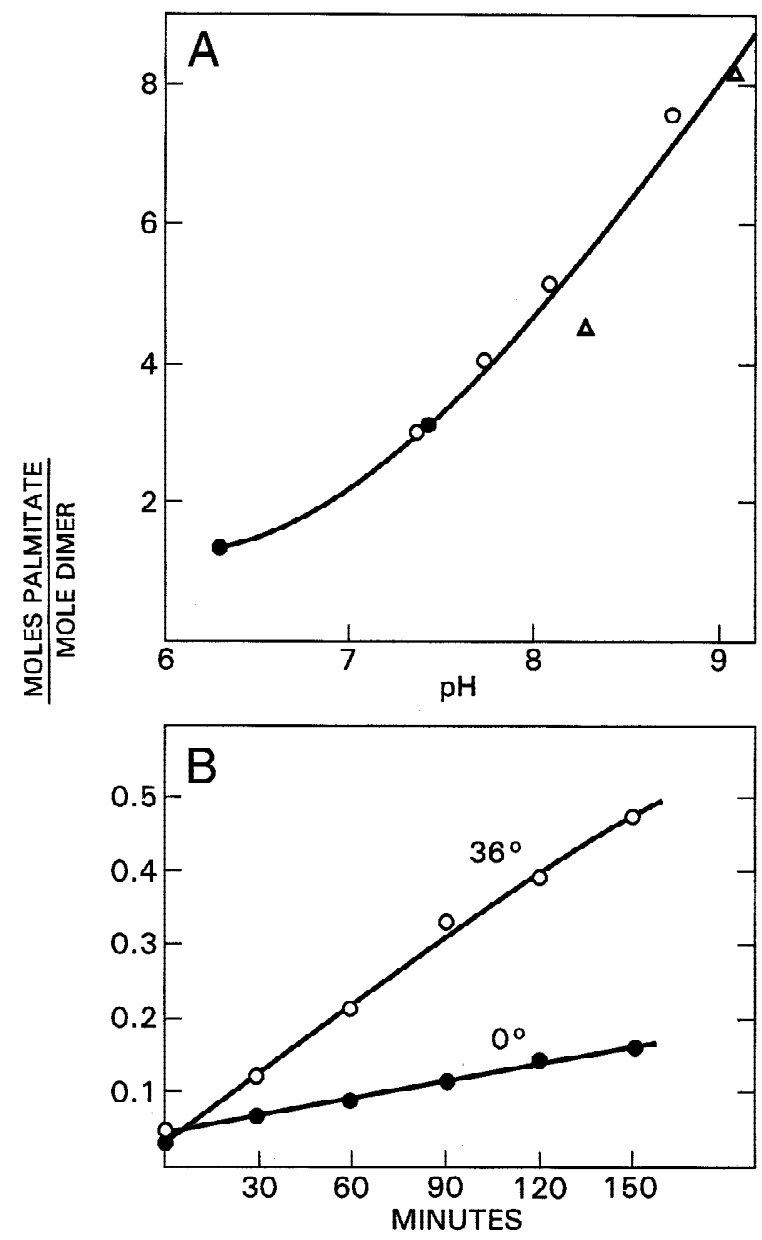

Fig. 3. A: Tubulin autopalmitoylation as a function of $\mathrm{pH}$. Nineteen micrometers tubulin was incubated for $2 \mathrm{~h}$ at $37^{\circ} \mathrm{C}$ with $1.0 \mathrm{mM}\left[{ }^{3} \mathrm{H}\right]$ palmitoyl CoA in three different buffers: $\operatorname{Mes}(\bullet)$, Tris $(\triangle)$, and glycine $(\mathrm{O})$, and processed with TCA as described in Materials and methods. B: Sixteen micrometers tubulin was incubated at 0 or $36^{\circ} \mathrm{C}$ in Tris buffer $\mathrm{pH} 7.6$ $\left.(+0.03 \% \text { Triton } \mathrm{X}-100,1 \mathrm{mM} \mathrm{MgCl})_{2}\right) \cdot\left[{ }^{3} \mathrm{H}\right]$ palmitoyl CoA was $35 \mu \mathrm{M}$.

centrations exceeded $0.045 \%$ (data not shown). Thus, the Triton $\mathrm{X}-100$ concentrations were kept at $0.03 \%$.

In contrast to what has been reported for enzymatic palmitoylation (Caron, 1997), a colchicine analogue (5-[2',3',4'-trimethoxyphenyl] tropone) or vinblastine, both at $30 \mu \mathrm{M}$, caused at most $25 \%$, and usually less, inhibition of palmitoylation, at both low and high loads of palmitoyl CoA.

\section{The role of the state of tubulin}

It is believed that the reactivity of sulfhydryl groups of tubulin toward alkylating agents is markedly reduced when the dimer is polymerized to microtubules (Ludueña \& Roach, 1981). Accordingly, we compared autopalmitoylation of dimeric tubulin with taxol-stabilized microtubules from which dimers had been removed by centrifugation. As shown in Figure 4A, little palmitate was transferred from palmitoyl CoA to microtubules after the initial burst, whereas a nearly linear uptake into dimers persisted for $2 \mathrm{~h}$ even under these high load conditions. When dimeric tubulin, palmitoyl CoA and taxol are co-incubated rather than using pre-

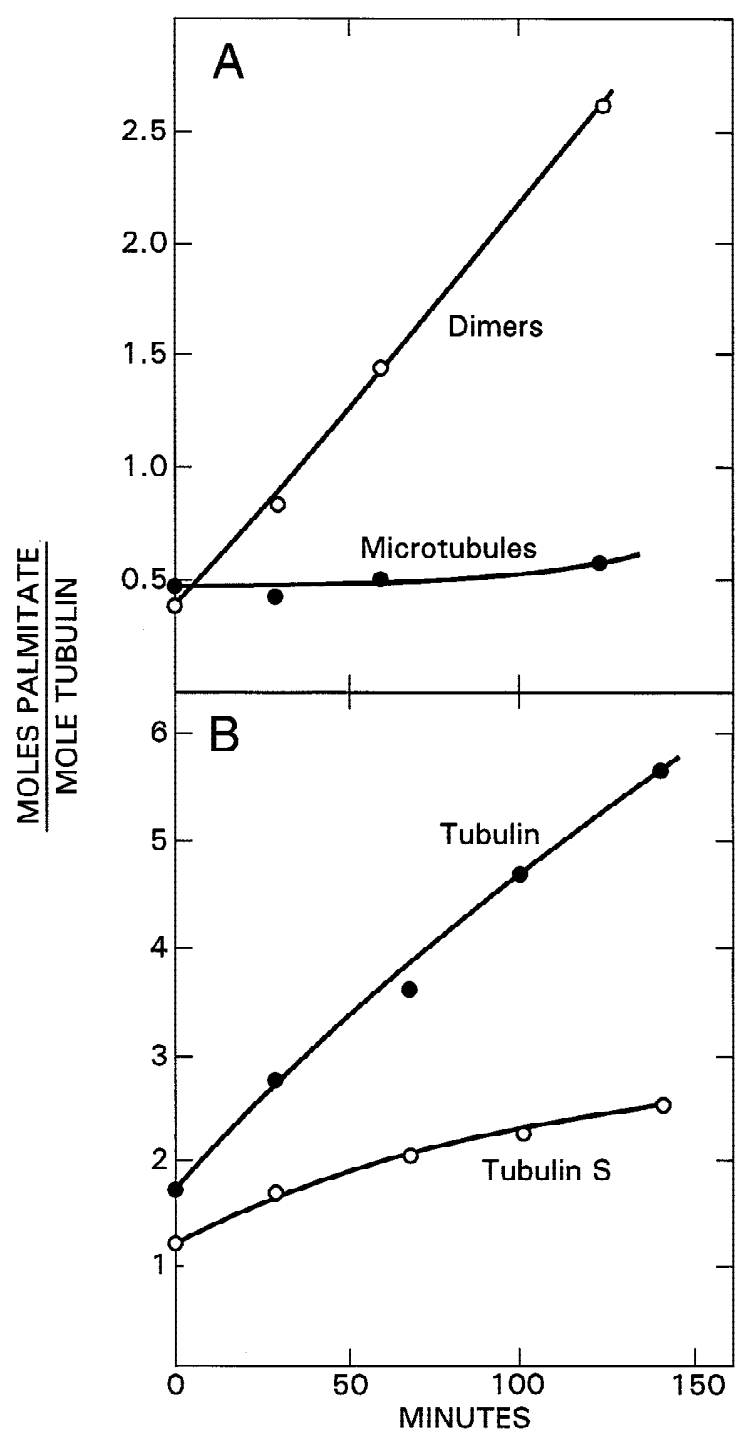

Fig. 4. The effect of the state of tubulin on autopalmitoylation. A: Comparison of tubulin dimers and microtubules as substrates for autopalmitoylation. Microtubules were formed in Mes assembly buffer, $\mathrm{pH}$ 6.9, containing $1 \mathrm{mM}$ GTP and $20 \mu \mathrm{M}$ taxol, collected in an Airfuge to remove residual dimers and resuspended in palmitoylation buffer. $10.3 \mu \mathrm{M}$ dimer protein and $12.1 \mu \mathrm{M}$ microtubule protein were incubated at $36^{\circ} \mathrm{C}$ with $312 \mu \mathrm{M}$ $\left[{ }^{3} \mathrm{H}\right]$ palmitoyl CoA. At indicated times samples were processed with TCA as described in Materials and methods. B: Comparison of autopalmitoylation of tubulin and tubulin S. Protein concentrations were $9.8 \mu \mathrm{M}$ for tubulin and $14.1 \mu \mathrm{M}$ for tubulin S. Incubation was at $36^{\circ} \mathrm{C}$ in $\mathrm{pH} 7.5$ Tris buffer $\left(+0.03 \%\right.$ Triton $\mathrm{X}-100$ and $\left.1 \mathrm{mM} \mathrm{MgCl}_{2}\right)$ and $1.0 \mathrm{mM}\left[{ }^{3} \mathrm{H}\right]$ palmitoyl CoA.

formed microtubules, the initial reaction is sufficiently rapid to permit substantial palmitate addition, presumably on the residual and not yet polymerized dimeric tubulin. It is not surprising, therefore, that the presence of $4 \mathrm{M}$ glycerol (which promotes tubulin polymerization) also markedly reduced autopalmitoylation (data not shown). It might be asked whether or not the presumably membrane targeted palmitoylated tubulin limits further in situ palmitoylation once in the membrane, either by saturation of available sites or by inaccessibility toward palmitoyl CoA. Preliminary experiments with membranes from PC12 pheochromocytoma cells 
showed modest palmitoylation of membrane tubulin (data not shown).

The properties of tubulin can also be altered by removal of the C-termini from both $\alpha$ and $\beta$ tubulin by limited subtilisin proteolysis yielding tubulin S (Bhattacharyya et al., 1985; Knipling et al., 1999). This procedure lowers the critical concentration for polymerization, changes the number of protofilaments in the microtubule, and certain other properties. When near equal concentrations of tubulin and tubulin S were autopalmitoylated, there was little difference in the initial fast component of palmitate incorporation (Fig. 4B), but the subsequent, slower accumulation of proteinbound palmitate was markedly attenuated in tubulin $\mathrm{S}$. While there was no gross turbidity during the incubation of palmitoyl CoA with the tubulin S preparation, $90^{\circ}$ light scattering measurements showed that polymerization to small polymers had occurred; this may possibly account for the reduced palmitoylation.

We have shown previously that when tubulin was subjected to stepwise denaturation by small increments of urea (Sackett et al., 1994), polymerization competence was lost early but several properties, such as ligand binding, were enhanced at low concentrations of the denaturant. At high urea concentrations, all functions were lost and the tryptophane spectrum revealed full exposure to the solvent. Consequently, we examined the possibility that urea might increase the accessibility of $\mathrm{SH}$ groups for palmitoylation. To our surprise, only a small increase in the mole ratio of palmitate to tubulin could be attained, and only at low concentrations of urea (Fig. 5, curve 1); there was no further increase with increasing urea

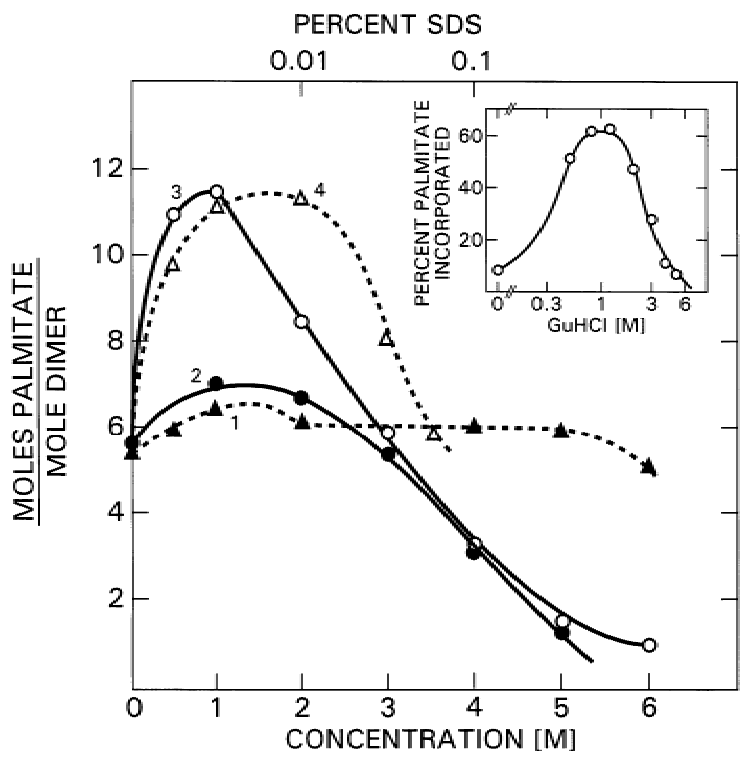

Fig. 5. The effect of denaturing agents on the autopalmitoylation of tubulin dimers. All reactions were carried out for $2 \mathrm{~h}$ at $37^{\circ} \mathrm{C}$ in Tris buffer $\mathrm{pH} 7.6$ containing $0.03 \%$ Triton $\mathrm{X}-100,1.0 \mathrm{mM} \mathrm{MgCl}_{2}$ and $500 \mu \mathrm{M}$ $\left[{ }^{3} \mathrm{H}\right]$ palmitoyl CoA. The tubulin concentration was $19.2 \mu \mathrm{M}$. Curve 1 , freshly prepared urea; curve 2 , sodium dodecyl sulfate (note different concentration scale at top of figure; curve 3 , guanidine hydrochloride; curve 4, potassium chloride. The SDS and $\mathrm{KCl}$ curves were normalized to the average controls of the urea and guanidine hydrochloride curves. Bound palmitate was determined with TCA as described above. Inset: A guanidine $\mathrm{HCl}$ concentration curve (logarithmic scale) for tubulin palmitoylation at $0.8 \mu \mathrm{M}\left[{ }^{3} \mathrm{H}\right]$ palmitoyl $\mathrm{CoA}$ is shown. concentrations and $8 \mathrm{M}$ urea was only minimally inhibitory (data not shown). Low concentrations of SDS (Fig. 5, curve 2) showed a similarly small enhancement of palmitoylation. However, there was marked inhibition as the concentration was raised to $0.3 \%$ or more. A similar inhibition of acylation by SDS has been shown (Bizzozero et al., 1987) for proteolipid protein and for UDP glucuronosyl transferase (Yamashita et al., 1995). In creatine kinase, on the other hand, SDS markedly increased SH accessibility (Clottes et al., 1994), hence the mechanism for SDS effects appears to be different for different proteins.

By contrast, exposure to progressively increasing levels of guanidine $\mathrm{HCl}$ (Fig. 5, curve 3) doubled the number of tubulin $\mathrm{SH}$ residues accessible for palmitoylation. This was followed by nearly total inhibition of palmitoylation at higher concentrations. The contrast to urea suggested that this stimulation might be due to a salt or ionic strength effect. Repetition of this experiment using $\mathrm{KCl}$ confirmed that supposition as $\mathrm{KCl}$ elicited a similar increase in palmitoylation, albeit at higher concentrations (Fig. 5, curve 4). An even more remarkable enhancement of tubulin palmitoylation by $\mathrm{GuHCl}$ is seen at low loads of palmitoyl CoA (Fig. 5, inset). Here, a nearly seven-fold increase in the $2 \mathrm{~h}$ incorporation of $\left[{ }^{3} \mathrm{H}\right]$ palmitate occurs at concentrations of $0.8-1.2 \mathrm{M} \mathrm{GuHCl}$. Similar biphasic salt effects have been observed for tubulin polymerization (Wolff et al., 1996a, 1996b). The inhibitory portion of the guanidine effect on palmitoylation may be partly due to the high ionic strength (Snyder et al., 1981, 1983), and the chaotropic effect of the chloride and/or guanidinium ions.

Tubulin "aged" for $18 \mathrm{~h}$ at room temperature, which leads to substantial loss of polymerization competence and colchicine binding activity (Wilson, 1975), exhibited only a $34 \%$ increase in autopalmitoylation at both low and high loads of palmitoyl CoA (data not shown). Purified, denatured $\alpha$ and $\beta$ monomers (electroeluted from SDS gels) were palmitoylated to about half the mole ratio as native dimer (data not shown). These results suggest that accessibility of SH groups may not be the chief limiting factor for palmitoylation. Rather, the neighboring amino acids in the primary sequence, as well as contribution from higher order structure, may have a significant effect on the reactivity of tubulin sulfhydryl groups toward palmitoyl CoA.

The effect of palmitoylation on $\alpha$ and $\beta$ tubulin is depicted in Figure 6. It is clear from Figure 6A that with increasing loads of palmitoyl CoA there is a general diminution in the staining of $\alpha$ tubulin and a compensatory increase in $\beta$ tubulin staining. Quantitative scans of these data (shown in Fig. 6B) suggest that a portion of the $\alpha$ tubulin has migrated at a more rapid rate into the $\beta$ tubulin band. The increase in $\beta$ tubulin staining is accompanied by a roughly commensurate increase in the moles of bound $\left[{ }^{3} \mathrm{H}\right]$ palmitate (calculated from the starting specific activity). This is shown in Figure 6C by a progressive decrease in the $\alpha / \beta$ ratio of bound palmitate. At low loads of palmitoyl CoA, the $\alpha / \beta$ ratio was slightly greater than 1.0. However, as loads were increased there was a progressive increase in the proportion of ${ }^{3} \mathrm{H}$ appearing in the $\beta$ band as expressed here by the ${ }^{3} \mathrm{H} \alpha / \beta$ ratio. The ${ }^{3} \mathrm{H}$ counts can be normalized to specific activities by use of the scanning data of Figure 6B. Table 1 compares the $\alpha / \beta$ ratios of incorporated palmitic acid before and after correction for protein content. It is evident that the changes in specific activity are substantially smaller than the changes in radioactivity. These data suggest strongly that palmitoylation leads to a marked mobility shift of $\alpha$ tubulin into the $\beta$ band, while there is only a small increase in mobility of $\beta$ tubulin seen at the highest loads as a broadened $\beta$ band. 


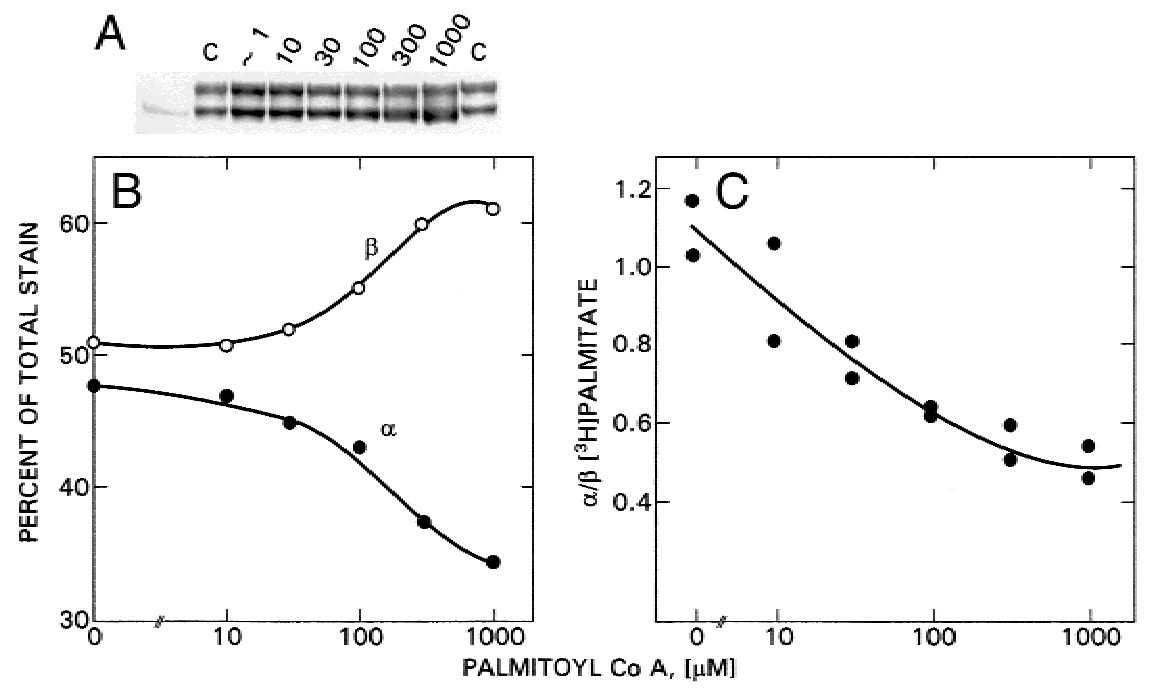

Fig. 6. The distribution of $\left[{ }^{3} \mathrm{H}\right]$ palmitate between $\alpha$ and $\beta$ tubulin. $19.5 \mu \mathrm{M}$ tubulin was incubated for $2 \mathrm{~h}$ at $37^{\circ} \mathrm{C}$ with different concentrations of $\left[{ }^{3} \mathrm{H}\right]$ palmitoyl CoA, electrophoresed at $20 \mathrm{~mA}$ on a $10 \%$ SDS gel to $30 \mathrm{~min}$ past expulsion of the dye front. Gels were stained with Coomassie R-250, scanned and quantitated with a Howtek Desktop Plus scanner using Density One software. A: Coomassie stain with untreated tubulin at either end. Concentrations of starting palmitoyl CoA are in $\mu \mathrm{M}$. C $=$ untreated native tubulin. B: Fraction of total Coomassie stain in the $\alpha$ and $\beta$ regions as a function of palmitoyl CoA concentrations; scans are derived from Figure 6A. C: The $\alpha / \beta$ ratio of the moles of $\left[{ }^{3} \mathrm{H}\right]$ palmitate incorporated into tubulin measured from the cut out and dissolved protein bands; points are from two separate experiments.

\section{Properties of palmitoylated tubulin}

Colchicine binding is a good index of the health of the tubulin dimer. For convenience we use the more rapidly binding colchicine analogue, 5-(2',3',4'-trimethoxyphenyl) tropone. Its binding was not affected by prior palmitoylation to a mole ratio of 5 ; the $\epsilon_{\max }$ for the bound analogue was identical, and there was $<3 \%$ loss in intensity (data not shown). Twenty or $30 \mu \mathrm{M}$ of the colchicine analogue or of vinblastine caused $<30 \%$ inhibition of palmitoyl CoA binding either at $\sim 1 \mu \mathrm{M}$ or $1 \mathrm{mM}$ loads of palmitoyl CoA. This is in contrast to reports of marked inhibition for enzymatic acylation of tubulin in platelets (Caron, 1997).

A more sensitive test of the normalcy of tubulin is its polymerization competence. It is well known that loss of 1-2 SH residues from the tubulin dimer by alkylation abolishes the ability to as-

Table 1. Palmitoylation shifts $\alpha$ tubulin into the $\beta$ tubulin band ${ }^{\mathrm{a}}$

\begin{tabular}{lcc}
\hline \hline $\begin{array}{l}\text { Palmitoyl } \\
\text { CoA added } \\
(\mu \mathrm{M})\end{array}$ & $\begin{array}{c}\alpha / \beta \text { Ratio for } \\
\text { bound palmitate }\end{array}$ & $\begin{array}{c}\alpha / \beta \text { Ratio for } \\
\text { bound palmitate } \\
\text { per unit tubulin } \\
\text { (area) }\end{array}$ \\
\hline$\sim 1$ & 1.09 & 1.186 \\
10 & 0.902 & 0.901 \\
30 & 0.752 & 0.856 \\
100 & 0.618 & 0.787 \\
300 & 0.565 & 0.922 \\
1000 & 0.481 & 0.847
\end{tabular}

${ }^{a}$ Data were calculated from Figure 6. Specific activities were calculated as DPM per area scanned. semble into microtubules (see recent summary by Phelps \& Walker, 2000). It is probable therefore that palmitoylation might have a similar effect even though the nature of the bond formed is different. We consequently tested assembly competence of tubulin after palmitoylation to 3-4 palmitic acids per dimer (at either $\mathrm{pH} 7.6$ or 6.9). During three cycles of polymerization/depolymerization, there was a progressive loss of specific activity $(\mathrm{dpm} / \mu \mathrm{g}$ protein). This suggests marked reduction in polymerization competence. Since similar losses occur with small alkylating agents (Phelps \& Walker, 2000), it is likely that this is due to loss of the same or similar critical $\mathrm{SH}$ residues rather than the presence of palmitic acid esters. Whether or not this change promotes membrane association in vivo by making the tubulin unavailable for microtubule assembly remains to be determined.

\section{The nature of the tubulin-palmitate bond}

While most studies find that the bulk of covalent palmitate in proteins exists as thioesters, as judged by neutral $1 \mathrm{M}$ hydroxylamine lability, a few reports have pointed to a residual, hydroxylamine-resistant, fraction of covalently protein-bound palmitate (Bizzozero et al., 1987; Alvarez et al., 1990; Degtyarev et al., 1993; Yamashita et al., 1995; Caron, 1997; Zambito \& Wolff, 1997). This might be hydroxylamine-resistant thioesters, oxyesters (defined as $\mathrm{KOH}-\mathrm{labile}$ ), or amides. By these definitions tubulin palmitoylation at both low or high loads yielded 63-73\% thioester, $15-19 \%$ oxyesters or resistant thioester, and $11-13 \% \mathrm{KOH}$ resistant linkages, presumably amide linkages to palmitate. Low palmitoyl CoA loads led to a somewhat higher proportion of thioester bonds and correspondingly lower proportion of other bonds. In an attempt to ascertain whether or not the hydroxylamine-resistant tubulin-bound palmitates were oxyesters or amides, we treated tubulin with DTNB such that 18.8 to $19.6 \mathrm{SH}$ groups per dimer had 
reacted. After purification, this derivative was subjected to acylation with a $1 \mathrm{mM}$ load of palmitoyl CoA. Compared to unmodified tubulin, the derivative bound only $4-6 \%$ as much palmitate in a $2 \mathrm{~h}$ incubation. This suggests that the $27-37 \%$ hydroxylamineresistant, tubulin-bound palmitate found above might, nevertheless, be present as thioesters. Moreover, the residual $\left[{ }^{3} \mathrm{H}\right]$ palmitate formed in the DTNB-treated tubulin was readily removed by $1 \mathrm{M}$ hydroxylamine. The possibility of a transfer to - $\mathrm{OH}$ or $-\mathrm{NH} 2$ groups requiring prior thioester formation in tubulin cannot, however, be ruled out. This type of transfer has been suggested for proteolipid protein acylation as a possible mechanism (Bizzozero et al., 1987), but we have no evidence at present that this occurs in tubulin. We are currently attempting to resolve this uncertainty by analysis of tryptic peptides; however, the marked increase in hydrophobicity has made their resolution difficult.

\section{Discussion}

A number of cytoplasmic proteins become reversibly associated with membranes through the participation of palmitate. It thus occurred to us that a lipid modification might account for the presence of the small, but significant, fraction of cellular tubulin in the plasma membrane (Feit \& Barondes, 1970; Bhattacharyya \& Wolff, 1975; Stephens, 1984). This fraction is firmly embedded because membrane residence alters the properties of tubulin (e.g., its increased thermal stability) and requires dissolution of the membrane to release the tubulin. The released tubulin regains its normal thermal stability (Bhattacharyya \& Wolff, 1975). Neither myristoylation nor prenylation can occur in tubulin, hence palmitoylation appeared to be the best candidate for a lipid modification promoting membrane association. Metabolic palmitoylation of tubulin has been shown to occur in platelets (Caron, 1997) and PC12 neuroblastoma cells (Zambito \& Wolff, 1997). We have recently shown that the plasma membrane of PC12 cells is the chief location of metabolically labeled tubulin (A.M. Zambito \& J. Wolff, in prep.). Stoichiometries could not, however, be determined. Autoacylation is known to occur (Wilson, 1975; Bizzozero et al., 1987; O’Brien et al., 1987; HartelSchenk \& Agre, 1992; Quesnel \& Silvius, 1994; Bharadwaj \& Bizzozero, 1995; Duncan \& Gilman, 1996; Ford et al., 1998; Veit et al., 1998). Caron (1997) has shown low levels of autoacylation of tubulin but no details were provided. For these reasons, enzymeindependent palmitoylation of tubulin was examined in detail.

Pure tubulin is acylated by palmitoyl CoA in a concentration-, $\mathrm{pH}-$, and temperature-dependent manner on both $\alpha$ and $\beta$ monomers. Although rat brain tubulin contains 12 cysteine residues in $\alpha$ tubulin and 8 in $\beta$ tubulin, the maximum level of substitution we could achieve under conditions compatible with native tubulin was 6-7 palmitates per dimer. The reason for the lack of reactivity of the remaining sulfhydryl groups is not clear. The marked reduction in palmitoylation of taxol-stabilized microtubules was expected due to burying of SH groups. We were, however, surprised that so many cysteine residues within the isolated dimer did not react with palmitoyl CoA, since other $\mathrm{SH}$ reagents such as mercurials or DTNB (Ikeda \& Steiner, 1978; Khan \& Ludueña, 1991; Faulstich et al., 1993) react with essentially all $20 \mathrm{SH}$ groups of the dimer. Even more surprising was the finding that urea denaturation of tubulin failed to increase accessibility of SH groups significantly. Stepwise denaturation with low concentrations of urea yielded, at most, 1-2 additional reactive cysteines. Even full denaturation with high concentrations of guanidine $\mathrm{HCl}$ or $1 \%$ SDS did not recruit additional cysteine residues for palmitoylation; in fact, they inhibited palmitoylation. Thus, while higher order structural effects (as exemplified in microtubules) have large effects on palmitoylation, only a third of the $20 \mathrm{SH}$ groups are available in the native dimer and denaturation does not make the remainder available for autoacylation. Hence, it seems unlikely that the residual SH groups are unreactive because they remain inaccessible to the solvent.

The local electrostatic environment of SH groups markedly influences their reactivity. It has been estimated that this factor may contribute as much as a $10^{6}$-fold spread in rate constants for disulfide exchange reactions (Snyder et al., 1981). In addition to the negative charge on the reactive thiolate anion, the effective local charge will be determined by appropriately positioned adjacent charged amino acids. These, plus the charge on the attacking sulfhydryl reagent, would be expected to have a major effect on the reactivity of the $\mathrm{SH}$ groups. An effective positive environment will favor attack by DTNB or palmitoyl CoA, whereas an effective negative environment will be expected to favor attack by dithiopyridines. Examples of cationic effects on reactions involving $\mathrm{SH}$ groups by increasing the nucleophilicity of the thiolate cation are readily available (Snyder et al., 1981, 1983; Parente et al., 1985). An example of probable anionic inhibition is provided by the absence of palmitoylation of glutathione at neutral $\mathrm{pH}$ (Bharadwaj \& Bizzozero, 1995). Moreover, these electrostatic effects will be enhanced in less polar regions of the protein, and many SH groups in proteins are near both basic and nonpolar amino acids. Note, however, that eight of the $\mathrm{SH}$ groups of the tubulin dimer are adjacent to or near aspartyl residues in the primary sequence, which will likely make them less reactive. The increased mole ratio of palmitate/tubulin seen after guanidine $\mathrm{HCl}$ or $\mathrm{KCl}$ could thus be viewed as a type of Debye-Hückel shielding of repulsive interactions near these $\mathrm{SH}$ groups. The increase in the mole ratio to $\sim 13$ at $\mathrm{pH}=10$ accomplishes the same result by increasing the fraction of SH groups present as thiolate anion. Thus, some of the resistance in tubulin SH palmitoylation may be related to this unfavorable environment.

Another factor is the charge and the reactivity of sulfhydryl reagents, and their electrostatic compatibility with the effective charge near the SH group. Comparison with DTNB (which we shall call a "strong" reagent) suggests that palmitoyl CoA must be judged to be a "weak" sulfhydryl reagent, i.e., one that reacts only with the more activated thiols. This would be expected to provide greater discriminating power between thiols of different reactivities and limit the degree of substitution. Thus, the three phosphates on $\mathrm{CoA}$, for example, may lead to greater charge repulsion by acidic neighbors of cysteine. To what extent the protein palmitoyl transferase can overcome these electrostatic limitations on the acylation reaction remains to be determined.

While the physiological significance of the high load experiments is not established, the reaction conditions for low load ("carrier-free") labeling experiments suggest that both structural (steric) and electrostatic effects play a role in the palmitoylation of tubulin. The total tissue levels of acyl CoAs are in the above range and may be increased by various stimuli (Ichihara \& Neely, 1985). Moreover, there is substantial noncovalent binding of palmitoyl CoA to tubulin (unpubl. obs.) and other proteins (Yamashita et al., 1995) that will enhance local concentrations. Similarly, higher palmitoyl CoA concentrations may be associated with the membrane. Thus, depending on the relative availability of this donor pool for enzymatic- vs. auto-palmitoylation of tubulin, the observed palmitoylation in platelet or PC 12 cells (Caron, 1997; Zambito \& Wolff, 1997) may be significantly contaminated by autoacylation, and it 
is difficult to exclude such autopalmitoylation within the cell. The distinction between these two types of palmitoylation may thus remain indeterminate (Duncan \& Gilman, 1996; Mollner et al., 1998; Veit et al., 1998). Moreover, the argument that enzymatic palmitoylation is faster than autopalmitoylation (Resh, 1999) will have to be examined for each cysteine in each protein since, e.g., the initial rates of tubulin autopalmitoylation (Figs. 1, 3, 4) were too fast to measure.

\section{Materials and methods}

Palmitoyl CoA, CoA, palmitoyl CoA synthase, taxol, colchicine, and vinblastine were obtained from Sigma Chemical Co. (St. Louis, Missouri); $\left[{ }^{3} \mathrm{H}\right]$ palmitic acid $(60 \mathrm{Ci} / \mathrm{mmol})$ was from American Radiolabeled Chemicals Inc. (St. Louis, Missouri); 2-methoxy-5$\left(2^{\prime}, 3^{\prime}, 4^{\prime}\right.$-trimethoxyphenyl) tropone was a gift of Dr. T.J. Fitzgerald. $\left[{ }^{3} \mathrm{H}\right]$ palmitoyl CoA was prepared according to Duncan and Gilman (1996), lyophilized and stored in liquid nitrogen. Pure (>99\%) rat brain tubulin was prepared as described (Wolff et al., 1996b), and tubulin $\mathrm{S}$ was prepared from this material as described by Knipling et al. (1999). $\alpha$ and $\beta$ monomers were separated by SDS gel electrophoresis under conditions to yield wide separation of the monomers, bands were cut out, electroeluted, and stored at $-20{ }^{\circ} \mathrm{C}$. Alternatively, the bands were dissolved in $300 \mu \mathrm{L}$ of $30 \% \mathrm{H}_{2} \mathrm{O}_{2}$ at $70{ }^{\circ} \mathrm{C}$, cooled, counting cocktail added, stored overnight to reduce chemiluminescence, and counted.

Samples were incubated at $37^{\circ} \mathrm{C}$ in $(0.08 \mathrm{M})$ Tris $\mathrm{HCl}$ buffer, $\mathrm{pH} 7.7$ (final $\mathrm{pH}$ after additions $=7.6$ ), containing $1 \mathrm{mM} \mathrm{MgCl} 2$ and $0.03 \%$ Triton X-100 (palmitoylation buffer). Tubulin was always added last. For zero times all samples were kept on ice until the first sample was taken immediately after protein addition. Aliquots were added to $600 \mu \mathrm{L}$ of cold $10 \%$ trichloracetic acid (TCA) in a $1.5 \mathrm{~mL}$ microtube, $10 \mu \mathrm{L}$ of tubulin $(320 \mu \mathrm{g})$ were added to the side of the tube and vortexed to assure formation of a fine precipitate. After $10 \mathrm{~min}$ on ice, tubes were centrifuged for $2 \mathrm{~min}$ at full speed on a microfuge. The supernatant solution was carefully removed, and the pellet was washed with 5\% TCA in 50\% ethanol (cold) containing $10 \mu \mathrm{L}$ of $1 \mathrm{mM}$ palmitoyl CoA for the first two washes. Samples were resuspended for $2 \mathrm{~min}$ in an ice bath with a sonicator and recentrifuged. Washing and pelleting were continued until the background for $30 \mu \mathrm{L}$ of supernatant was $<100 \mathrm{dpm}$. The final pellets were dissolved in $30 \mu \mathrm{L}$ of $2 \mathrm{M}$ $\mathrm{NaOH}, 70 \mu \mathrm{L}$ of water was added, and the solutions were transferred to counting vials. The tubes were rinsed once with $100 \mu \mathrm{L}$ of $0.1 \mathrm{M} \mathrm{KOH}$ in methanol, washings were added to the counting vials, and $5 \mathrm{~mL}$ of a scintillation cocktail were added before counting, generally to a counting error of $<2 \%$. Calculations were based on the counts recovered in the pellet and the starting specific activity. SDS gel electrophoresis was carried out as described (Knipling et al., 1999). For determination of the nature of the bonds, triplicate gels were exposed overnight to $0.1 \mathrm{M}$ Tris buffer $\mathrm{pH} 7.5,1 \mathrm{M}$ neutral $\mathrm{NH}_{2} \mathrm{OH}$ or methanolic $\mathrm{KOH}(0.1 \mathrm{M})$, fixed, washed, stained, and prepared for counting as previously described (Zambito \& Wolff, 1997).

Quantitative reaction of tubulin sulfhydryl groups was carried out with DTNB using a DTNB/SH ratio of 2 . Five hundred microliters were incubated at $37^{\circ} \mathrm{C}$ for $2 \mathrm{~h}$ followed by addition of $500 \mu \mathrm{L}$ of saturated ammonium sulfate (added dropwise) and left on ice for $45 \mathrm{~min}$. The precipitate was collected at 13,000 $\mathrm{g}$ for 2 min and washed with $50 \%$ saturated ammonium sulfate until the absorption spectrum equaled that of ammonium sulfate alone. The pellet was dissolved in Mes assembly buffer (0.1 M Mes pH 6.9, $1.0 \mathrm{mM} \mathrm{MgCl} 2,1.0 \mathrm{mM}$ EGTA) and was dialyzed first against water then against Mes assembly buffer. Protein concentration was determined and the sample was frozen in liquid nitrogen until used. The degree of substitution was calculated using $\epsilon_{412}=14,150$ $\mathrm{M}^{-1} \mathrm{~cm}^{-1}$ for the released 2-nitro-5-thiobenzoate (Faulstich et al., 1993). Subsequent palmitoylation with $1.0 \mathrm{mM}\left[{ }^{3} \mathrm{H}\right]$ palmitoyl CoA was carried out as above.

\section{References}

Alvarez E, Gironès N, Davis RJ. 1990. Inhibition of the receptor-mediated endocytosis of diferric transferrin is associated with the covalent modification of the transferrin receptor with palmitic acid. J Biol Chem 265:1664416655 .

Bañó MC, Jackson CS, Magee AI. 1998. Pseudo-enzymatic S-acylation of a myristoylated Yes protein tyrosine kinase peptide in vitro may reflect nonenzymatic S-acylation in vivo. Biochem J 330:723-731.

Bharadwaj M, Bizzozero OA. 1995. Myelin $\mathrm{P}_{\mathrm{O}}$ glycoprotein and a synthetic peptide containing the palmitoylation site are both autoacylated. J Neurochem 65:1805-1815.

Bhattacharyya B, Sackett DL, Wolff J. 1985. Tubulin, hybrid dimers, and tubulin S. J Biol Chem 260:10208-10216.

Bhattacharyya B, Wolff J. 1975. Membrane-bound tubulin in brain and thyroid tissue. J Biol Chem 250:7639-7646.

Bizzozero OA, McGarry JF, Lees MB. 1987. Autoacylation of myelin proteolipid protein with acyl coenzyme A. J Biol Chem 262:13550-13557.

Caron JM. 1997. Posttranslational modification of tubulin by palmitoylation: I. In vivo and cell-free studies. Mol Biol Cell 8:621-636.

Chapman ER, Blasi J, An S, Brose N, Johnston PA, Sudhoff TC, Jahn R. 1996. Fatty acylation of synaptotagmin in PC12 cells and synaptosomes. Biochem Biophys Res Commun 225:326-332.

Clottes E, Couthon F, Denoroy L, Vial C. 1994. Creatine kinase compactness and thiol accessibility during sodium dodecyl sulfate denaturation estimated by resonance energy transfer and 2-nitro-5-thiocyanobenzoic acid cleavage. Biochim Biophys Acta 1209:171-176.

Crampton MR. 1974. In: Patai S, ed. The chemistry of the thiol group. Vol. 1. London: John Wiley \& Sons. pp 379-415.

Degtyarev MY, Spiegel AM, Jones TLZ. 1993. The G protein $\alpha_{\mathrm{S}}$ subunit incorporates $\left[{ }^{3} \mathrm{H}\right]$ palmitic acid and mutation of cysteine- 3 prevents this modification. Biochemistry 32:8057-8061.

Duncan JA, Gilman AG. 1996. Autoacylation of G protein $\alpha$ subunits. J Biol Chem 271:23594-23600.

Dunphy JT, Linder ME. 1998. Signalling functions of protein palmitoylation. Biochim Biophys Acta 1436:245-261.

Faulstich H, Tews P, Heintz D. 1993. Determination and derivatization of protein thiols by n-octyl dithionitrobenzoic acid. Anal Biochem 208:357-362.

Feit H, Barondes SH. 1970. Colchicine-binding activity in particulate fractions of mouse brain. J Neurochem 17:1355-1364.

Ford DA, Horner CC, Gross RW. 1998. Protein kinase C acylation by palmitoyl coenzyme A facilitates its translocation to membranes. Biochemistry 37: $11953-11961$.

Friedman M. 1973. The chemistry and biochemistry of the sulfhydryl group in amino acids, peptides and proteins. Oxford, UK: Pergamon Press.

Gunderson CB, Mastrogiacomo A, Faull K, Umbach JA. 1994. Extensive lipidation of a Torpedo cysteine string protein. J Biol Chem 269:19197-19199.

Hartel-Schenk S, Agre P. 1992. Mammalian red cell membrane Rh polypeptides are selectively palmitoylated subunits of a macromolecular complex. J Biol Chem 267:5569-5574.

Ichihara K, Neely JR. 1985. Recovery of ventricular function in reperfused ischemic rat hearts exposed to fatty acids. Am J Physiol 249 (3 part 2):H492-H497.

Ikeda Y, Steiner M. 1978. Sulfhydryls of platelet tubulin: Their role in polymerization and colchicine binding. Biochemistry 17:3454-3459.

Khan IA, Ludueña RF. 1991. Possible regulation of the in vitro assembly of bovine brain tubulin by the bovine thioredoxin system. Biochim Biophys Acta 1076:289-297.

Knipling L, Hwang J, Wolff J. 1999. Preparation and properties of pure tubulin S. Cell Motil Cytoskel 43:63-71.

Ludueña RF, Roach MC. 1981. Interaction of tubulin with drugs and alkylating agents. 1. Alkylation of tubulin by iodo $\left[{ }^{14} \mathrm{C}\right]$ acetamide and $\mathrm{N}, \mathrm{N}^{\prime}$ ethylenebis (iodoacetamide). Biochemistry 20:4437-4444.

Magee AI, Gutierrez L, Marshall, CJ, Hall A. 1987. Dynamic fatty acylation of p2 $1^{\mathrm{N}-\mathrm{ras}}$. EMBO J 6:3353-3357. 
Milligan G, Parenti M, Magee AI. 1995. The dynamic role of palmitoylation in signal transduction. TIBS 20:181-186.

Mollner S, Ferreira P, Beck K, Pfeuffer T. 1998. Nonenzymatic palmitoylation at Cys 3 causes extra-activation of the $\alpha$-subunit of the stimulatory GTPbinding protein $\mathrm{G}_{\mathrm{S}}$. Eur J Biochem 257:236-241.

O'Brien PJ, St. Jules RS, Reddy TS, Bazan NG, Zatz M. 1987. Acylation of disc membrane rhodopsin may be nonenzymatic. J Biol Chem 262:5210_ 5215

Omary MB, Trowbridge IS. 1981. Biosynthesis of the human transferrin receptor in cultured cells. J Biol Chem 256:12888-12892.

Parente A, Merrifield B, Geraci G, D'Alessio G. 1985. Molecular basis of superreactivity of cysteine residues 31 and 32 of seminal ribonuclease. Biochemistry 24:1098-1104.

Quesnel S, Silvius JR. 1994. Cysteine-containing peptide sequences exhibit facile uncatalyzed transacylation and acyl-coA-dependent acylation at the lipid bilayer interface. Biochemistry 33:13340-13348.

Phelps KK, Walker RA. 2000. NEM tubulin inhibits minus end assembly by a reversible cap. Biochemistry 39:3877-3885.

Resh MD. 1999. Fatty acylation of proteins: New insights into membrane targeting of myristoylated and palmitoylated proteins. Biochim Biophys Acto 1451:1-18.

Sackett DL, Bhattacharyya B, Wolff J. 1994. Local unfolding and the stepwise loss of the functional properties of tubulin. Biochemistry 33:12868-12878

Snyder GH, Cennerazzo MJ, Karalis AJ, Field D. 1981. Electrostatic influence of local cysteine environments on disulfide exchange kinetics. Biochemistry 20:6509-6519.

Snyder GH, Reddy MK, Cennerazzo MJ, Field D. 1983. Use of local electrostatic environments of cysteines to enhance formation of a desired species in a reversible disulfide exchange reaction. Biochim Biophys Acta 749:219226.

Stephens RE. 1984. Membrane tubulin. Biol Cell 57:95-110.

Sudo Y, Valenzuela D, Beck-Sickinger AG, Fishman MC, Strittmatter SM. 1992 Palmitoylation alters protein activity: Blockade of $\mathrm{G}_{\mathrm{O}}$ stimulation by GAP43. EMBO J 11:2095-2102.

Tao N, Wagner SJ, Lublin DM. 1996. CD36 is palmitoylated on both N- and C-terminal cytoplasmic tails. J Biol Chem 271:22315-22320.

Veit M, Sachs K, Heckelman M, Maretzki D, Hofmann KP, Schmidt MFG. 1998. Palmitoylation of rhodopsin with S-protein acyl transferase: Enzyme catalyzed reaction versus autocatalytic acylation. Biochim Biophys Acta 1394:90-98

Weimbs T, Stoffel W. 1992. Proteolipid protein (PLP) of CNS myelin: Positions of free, disulfide-bonded, and fatty acid thioester-linked cysteine residues and implications for the membrane topology of PLP. Biochemistry 31:1228912296.

Wilson L. 1975. Microtubules as drug receptors: Pharmacological properties of microtubule protein. Ann NY Acad Sci 253:213-231.

Wolff J, Knipling L, Sackett DL. 1996b. Charge-shielding and the "paradoxical" stimulation of tubulin polymerization by guanidine hydrochloride. Biochemistry 35:5910-5920.

Wolff J, Sackett DL, Knipling L. 1996a. Cation selective promotion of tubulin polymerization by alkali metal chlorides. Protein Sci 5:2020-2028.

Yamashita A, Watanabe M, Tonegawa T, Sugiura T, Waku K. 1995. Acyl-coA binding and acylation of UDP-glucuronyl transferase. Biochem J 312:301308.

Zambito AM, Wolff J. 1997. Palmitoylation of tubulin. Biochem Biophys Res Commun 239:650-654. 